\title{
The Safety and Efficacy of Mini Percutaneous Nephrolithotomy During Learning Curve
}

\author{
Bikash Bikram Thapa', Bina Basnet ${ }^{2}$, Bikash Bahadur Rayamajhi', Narayan Thapa' ${ }^{1}$ and \\ Bharat Bahadur Bhandari ${ }^{1}$
}

\begin{abstract}
${ }^{1}$ Department of Surgery, Nepalese Army Institute of Health Sciences, Shree Birendra Hospital, Chhauni, Kathmandu, Nepal

${ }^{2}$ Department of Radiology, Nepalese Army Institute of Health Sciences, Shree Birendra Hospital, Chhauni, Kathmandu, Nepal
\end{abstract}

\section{ABSTRACT}

Introduction: Since its introduction in 1976, percutaneous renal stone surgery has undergone several modifications. Reduction in size of access sheath was one of them which was first reported by Jackman in 1998. The miniaturisation of access sheath in Mini-Percutaneous Nephrolithotomy surgery has significantly reduced the intervention related morbidity with similar outcome as of standard Percutaneous Nephrolithotomy. Methods: This is a prospective cohort study where a single surgeon without previous experience of independent PCNL surgery performed Mini PCNL under controlled condition for renal stone sized 10 to 30 $\mathrm{mm}$. The outcome was measured in terms of stone free rate and postoperative complications. The association of stone free rate and drop in haemoglobin level with different preoperative and operative variables were calculated with Pearson's correlation test and $\mathrm{p}$ value $<0.05$ was considered significant.

Results: Mini PCNL was performed in total of 63 renal units. The mean age was $37.8 \pm 9.9$ years with male: female ratio of $1.8: 1$. The average stone size was $16.8 \pm 2.9 \mathrm{~mm}$. The mean operative time was $55.2 \pm 19.0$ (30-110) minutes. The stone free rate was $98.2 \pm 3.6 \%$. The mean drop in haemoglobin was $1.3 \pm 0.8$ and blood transfusion rate was $4.7 \%$. The average hospital stay was $2.6 \pm 1.3$ days. The grade I complications was $15.8 \%$ and grade II and III was $7.9 \%$ each. Stone free rate was significantly associated with stone number $(r=-0.47, p=0.004)$. Similarly fall in haemoglobin was associated with total operative time $(r=0.49$, $\mathrm{p}=0.003)$. The stone size, hardness of stone (HU) and size of access sheath had no significant association with stone free rate and fall in haemoglobin.

Conclusions: Mini PCNL is as effective as standard PCNL with higher safety margin in small and medium size stone (10 to $30 \mathrm{~mm}$ ) during learning curve of endo-urology procedure.

Key words: complications; learning curve; PCNL; stone free rate

Correspondence: Bikash Bikram Thapa, Department of Surgery, Nepalese Army Institute of Health Sciences, Shree Birendra Hospital, Chhauni, Kathmandu, Nepal. Email: bikashbikram.thapa@naihs.edu.np

DOI: http://dx.doi.org/10.3126/mjsbh.v18i2.21355

Submitted on: 2018-10-14

Accepted on: 2019-04-06

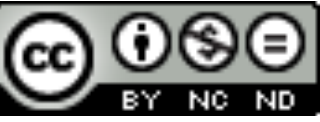

This work is licensed under creative common license:

http://creativecommons.org/licenses/by-nc-nd/4.0/ (C) MJSBH 2019 


\section{INTRODUCTION}

The prevalence of urolithiasis is estimated to be $5 \%$ to $10 \%$ in USA and $11 \%$ in Turkey. ${ }^{1}$ Urolithiasis is quite common disease in Nepal due to its unique climate and socio-economic status. ${ }^{2}$ Chand RB et al. in his research stated that nephrolithiasis comprises $68.7 \%$ of urology patients with overall higher prevalence in females than males (1.35:1). Majority $(71.9 \%)$ were economically productive age group of 20-60 years. ${ }^{2}$ Percutaneous Nephrolithotomy (PCNL), introduced in 1976 is the standard of care for nephrolithiasis with size more than $2 \mathrm{~cm}$ and option for stone with size 1 to $2 \mathrm{~cm}$ size. Fernström and Johansson were the first to extract the renal stone through percutaneous route under radiological control. ${ }^{3}$

Bleeding (11.2-17.5\%), extravasations of urine (7.2\%) and fever (21.0-32.1\%) are the most common complications of PCNL surgery. ${ }^{4}$ Reducing the sheath size and hence the tissue trauma results in reduced bleeding during PCNL. Standard PCNL is done with sheath size of 24-30 F whereas the Mini PCNL/Miniperc is done with sheath size 14-20 F. ${ }^{5}$ The result of very first Mini PCNL in adult patients $(\mathrm{n}=7)$ using access sheath of $13 \mathrm{Fr}$ had encouraging result with stone free rate of $89 \%{ }^{6}$ Bhattu et al. states, "Miniperc quickens the recovery after PCNL with lesser haemoglobin drop, more probability of tubeless procedures, less analgesic requirement, and lesser hospital stay."7

An important aspect among surgeons performing PCNL is its learning curve. The "learning curve" is defined as a graph that represents the progress in the mastery of a skill against the time required for such mastery. Studies suggest that the surgical competence in PCNL can be reached after 60 cases and excellence after 115 cases. ${ }^{8,9}$ However the clinically relevant endpoints for PCNL are the rates of stone clearance and major complications. Since the safety and efficacy of MiniPCNL over Standard PCNL are well documented in different randomised trials we plan to evaluate the same during learning curve of a surgeon.

\section{METHODS}

This was a prospective cohort study where a single surgeon without previous experience of independent PCNL surgery performed Mini PCNL. These Mini PCNL surgeries were done under supervision of an expert surgeon who had done more than 300 PCNL. The end point of the study was $60^{\text {th }}$ case (August 2016 to September 2018). Patients with age more than 18 years, renal stone size of 10 to $30 \mathrm{~mm}$ in maximum dimension were included. Patient with congenital renal anomalies, solitary kidney and documented urinary tract infection were excluded. The study was conducted after ethical clearance from Institutional Review Board and informed consent of patient.

The diagnosis of nephrolithiasis was established with plain X-ray KUB (Kidney, Ureter and Bladder), Ultrasound KUB and Non-Contrast Computed Tomography KUB. Urine culture sensitivity was done for all patients and urine sterility ensured before undertaking Mini PCNL. Stone free rate was defined as absence of residual fragments $>3 \mathrm{~mm}$. A single dose third generation cephalosporins was given to all patients at the induction of anaesthesia. A 6 Fr ureteric catheter was inserted in lithotomy position. Patient was taken in prone position. The optimal calyx was determined under fluoroscopy after retrograde injection of the diluted contrast (1:3) through ureteric catheter and puncture done with $18 \mathrm{G}$ needle with triangulation technique. $0.38 \% / 150 \mathrm{~cm}$ straight tip hydrophilic guide wire (HiWire Nitinol Core Wire Guide, $\mathrm{COOK}^{\circledR}$ ) parked and the tract was dilated with fascial dilators (Blueneem Tech.) Mini PCNL was performed with access sheath of 16, 18 or $20 \mathrm{Fr}$ (Blueneem Tech.). A 9.5/11.5 Fr, ureteroscope (Karl Storz, Germany) with pneumatic lithotripsy (NIDHI ${ }^{\circledR}$ Meditech System) was used to fragment the stones. An irrigation pump (Karl Storz, endomat LC, 203303 20) was used for saline irrigation. Stone fragments were retrieved passively with help of hydraulic pressure or actively using grasping forceps. At the end of the procedure in both groups, clearance of stones was confirmed by nephroscopy and fluoroscopy. 
A $26 \mathrm{~cm}, 6 \mathrm{Fr}$ double-J (DJ) ureteric stent or a ureteric catheter and/or a nephrostomy (PCN) tube were left according to presence of intraoperative complications, expected residual stones and/or planning for a second-look session. Discharge of the patients was decided after successive removal of PCN /Ureteric catheter in the presence of clear urine. Postoperative X-ray KUB was done to see residual stones and position of DJ-stent. X-ray KUB and Ultrasound KUB were done one month post-operatively to evaluate residual stones and percentage of stone free rate was calculated. DJ stent were removed 4 weeks post-operatively. Patients' demographic details were noted. Size of stone (maximum dimension), Hounsfield unit of stone, number, and laterality noted. Operative details recorded were site of puncture, access sheath size, operative time (skin puncture to removal of sheath). Failure to calyceal puncture was noted. Postoperative drop in haemoglobin and complications were noted. Complications were graded according to Clavein Dindo classification.

The data were presented in mean $\pm \mathrm{SD}$. Mean drop in haemoglobin, total hospital stay, number of tubeless Mini PCNL, need of auxillary procedure presented. The statistical analysis was done with SPSS. The association of Stone free rate and drop in haemoglobin level with different preoperative and operative variables were calculated with Pearson's correlation test and $\mathrm{p}$ value $<0.05$ was considered significant.

\section{RESULTS}

Mini PCNL was performed in total of 63 Renal units. The mean age was $37.8 \pm 9.9$ years with male: female ratio of $1.8: 1$. The stone characteristics and operative details are presented in table 1 and table 2 . The mean operative time was $55.2 \pm 19.0(30-110)$ minutes. $47 \%$ of the cases were concluded as tubeless Mini PCNL. The stone free rate was $98.2 \pm 3.6 \%$. The mean drop in haemoglobin was $1.3 \pm 0.8$ and blood transfusion rate was $4.7 \%$. The average hospital stay was $2.6 \pm$ 1.3 days. The rate of complications according to Clavein Dindo grading is presented in table 3. The grade I or Grade II complications are $15.8 \%$ and
Table 1. Patient and stone characteristics

\begin{tabular}{|l|l|l|}
\hline Variables & Average & Range \\
\hline Number of patient & 60 & \\
\hline Number of Renal Unit & 63 & \\
\hline Sex (Male: Female) & $1.8: 1(45: 25)$ & $24-64$ \\
\hline Age (Years) & $37.8 \pm 9.9$ & $12-26$ \\
\hline Size of stone (mm) & $\begin{array}{l}16.8 \pm 2.9 \\
\text { Single }=33 \\
\text { Multiple }=27\end{array}$ & $1-3$ \\
\hline Number of stone & $\begin{array}{l}\text { Right }=25 \\
\text { Left }=35 \\
\text { Bilateral }=3\end{array}$ & \\
\hline Laterality & $\begin{array}{l}\text { None }=10 \\
\text { Mild }=32 \\
\text { Moderate }=21\end{array}$ & $\begin{array}{l}\text { 1173.00 } \pm 161.20 \\
1199-1568\end{array}$ \\
\hline Hydronephrosis &
\end{tabular}

$7.9 \%$ respectively. Out of Grade III complications $(7.9 \%)$, two patients underwent uretero-rensoscopic for steinstrasse, two patients underwent repositioning of double $\mathrm{J}$ stent and one patient underwent urinary bladder wash and clot evacuation twice for delayed haemorrhage. The failure to puncture was four $(6.3 \%)$ where assistance from supervisor is taken. Stone number has significant association with stone free rate $(\mathrm{r}=$ $-0.47, p=0.004)$. Similarly fall in haemoglobin was associated with total operative time $(r=0.49$, $\mathrm{p}=0.003)$. The stone size, hardness of stone (HU) and size of access sheath had no significant association with stone free rate and fall in haemoglobin.

\section{DISCUSSION}

The Mini PCNL was first performed in paediatric patients. Later the first Mini PCNL in adult, using small access sheath (13 Fr) with miniature instrument (6.9 Fr /7.2 Fr urteroscope or 7.7 Fr paediatric cystoscope) was performed by Jackman in 1997, which played a lead role in establishment of Mini Percutaneous Nephrolithotomy. ${ }^{6}$ Lahme ${ }^{10}$ recommended Mini PCNL to treat all kinds of upper urinary tract calculi $>10 \mathrm{~mm}$ in diameter and is regarded as a treatment alternative to flexible ureterorenoscopy, SWL and conventional PCNL. 
Table 2. Operative details of Mini PCNL $(n=63)$

\begin{tabular}{|c|c|c|}
\hline \multicolumn{3}{|l|}{ Operative details } \\
\hline Skin puncture & $\begin{array}{l}\text { Single }=47 \\
\text { Multiple }=16\end{array}$ & \\
\hline Calyceal puncture & $\begin{array}{l}\text { Upper }=11 \\
\text { Middle }=39 \\
\text { Lower }=8 \\
\text { Failure }=5\end{array}$ & \\
\hline Sheath size (Fr) & $\begin{array}{l}16 \mathrm{Fr}=13 \\
18 \mathrm{Fr}=43 \\
20 \mathrm{Fr}=7\end{array}$ & \\
\hline $\begin{array}{l}\text { Mean fluoroscopy } \\
\text { time (min) }\end{array}$ & $18.32 \pm 6.20$ & $10-28 \mathrm{~min}$ \\
\hline $\begin{array}{l}\text { Mean operative time } \\
(\mathrm{min})\end{array}$ & $55.2 \pm 19.0$ & $\begin{array}{l}30-110 \\
\min \end{array}$ \\
\hline PCN tube & $\begin{array}{l}\text { Yes }=30(47 \%) \\
\text { No }=33(53 \%)\end{array}$ & \\
\hline $\begin{array}{l}\text { Mean stone free rate } \\
(\%)\end{array}$ & $98.2 \pm 3.6$ & $90-100 \%$ \\
\hline $\begin{array}{l}\text { Mean drop in } \\
\text { haemoglobin }(\mathrm{gm} \%)\end{array}$ & $1.3 \pm 0.8$ & $0.5-3.5 \mathrm{gm} \%$ \\
\hline $\begin{array}{l}\text { Mean total hospital } \\
\text { stay (days) }\end{array}$ & $2.6 \pm 1.3$ & 2-7 days \\
\hline
\end{tabular}

Mini PCNL had similar stone free rate but lesser complications rate than standard PCNL for stone size $<20 \mathrm{~mm}$. Mini PCNL had significant advantage over standard PCNL in terms of reduced bleeding (mean haemoglobin drop of $0.8 \mathrm{mg} \%$ ) leading to higher chance of tubeless procedure (75-80\%) and reduced hospital stay (2.43-4.5 days). ${ }^{11-14}$ The operative time for Mini PCNL was found to be 45-69 minutes which was higher than standard PCNL but statistically insignificant ( $p$ $>0.3){ }^{11,12}$ Kukreja et al. ${ }^{15}$ demonstrated similar safety and efficacy in his prospective randomised study in management of adult nephrolithiasis of size 15 to $30 \mathrm{~mm}$ with no difference in operative time between standard and Mini PCNL. A review of more than 10,000 cases revealed a stone-free rate of $86.7 \%$ and $86.1 \%$ for simple and complicated stones respectively following Mini PCNL. ${ }^{16}$ For simple renal stone SFR as high as $93-96 \%$ was reported. ${ }^{11,15}$ The higher rate of SFR in our series was due to selected size and lesser burden of stone. The tubeless PCNL had similar rate of total hospital stay, mean post-operative haemoglobin drop, post-
Table 3. Complications (Clavein -Dindo Grade)

\begin{tabular}{|c|c|}
\hline \multicolumn{2}{|l|}{ Clavein -Dindo Grade } \\
\hline Grade I & $10 / 15.8 \%$ \\
\hline Injury to PCS & $3(4.7 \%)$ \\
\hline Fever & $3(4.7 \%)$ \\
\hline Pleural effusion & $2(3.1 \%)$ \\
\hline Urine leak & $2(3.1 \%)$ \\
\hline Grade II & $5 / 7.9 \%$ \\
\hline Blood transfusion & $3(4.7 \%)$ \\
\hline Urosepsis & $2(3.1 \%)$ \\
\hline Grade III & $5 / 7.9 \%$ \\
\hline Delayed hemorrhage & $1(1.5 \%)$ \\
\hline Displaced DJ & $2(3.1 \%)$ \\
\hline Steinstrasse & $2(3.1 \%)$ \\
\hline
\end{tabular}

operative urine leakage and stone free rate but had less post-operative analgesic requirement. ${ }^{17} \mathrm{We}$ managed to perform tubeless PCNL, in 53\% patients with similar outcome. Out of 33 tubeless PCNL, nine of our cases were done total tubeless (without PCN tube and DJ stent) where ureteric catheter was left in situ and removed in first or second postoperative day.

Even a complex stone burden can be safely and efficiently managed with Mini PCNL . ${ }^{12,}{ }^{13}$ In our series the stone free rate was significantly associated with number of stones $(p=0.004)$ and weakly associated with size $(p=0.3)$ and hardness $(p=0.2)$. Stone free rate was significantly lower with multiple calyceal stones in case of Mini PCNL. ${ }^{13}$ Stone free rate (SFR) had strong association with stone numbers and burden. SFR of stone size $\quad<2 \mathrm{~cm}^{2}$ and $>2 \mathrm{~cm}^{2}$ was found to be $96.9 \%$ and $88.5 \%$ respectively. Similarly, the SFR for multiple stones was $79.6 \%$ to $83.9 \%$ and SFR for single stone was $95.1 \%$. And there was significant difference in SFR between two types of intervention (Mini PCNL vs Standard PCNL), in patients with multiple stone $(p=0.018)$ or stone burden $>2 \mathrm{~cm}^{2}(\mathrm{p}=0.026)$ only. ${ }^{12}$ 
In a study designed to evaluate the outcome of 10,000 Mini PCNL with $16 \mathrm{Fr}$ access sheath complications occurred in 275 out of 1368 patients (20.1\%). ${ }^{16}$ There were 102 Clavien grade I (7.4\%), 121 grade II $(8.8 \%)$ and 48 grade III $(3.5 \%)$ complications, but no grade IV or V complications. $82.0 \%$ of cases had complete stone clearance without undergoing further PCNL. Mini PCNL had blood transfusion rate of 1.6 to $3.7 \% .^{12,13,16}$ In our series mean drop in haemoglobin percentage was higher $(1.3 \pm 0.8 \%)$ than other studies ${ }^{11}{ }^{15}$ which had significant association with operative time $(\mathrm{r}=$ 0.49 and $\mathrm{p}=0.003)$. A statistically significant decrease in haemoglobin with prolonged operative time $(\mathrm{p}<0.041)$ can happen. ${ }^{7}$

In our study overall five (7.9\%) patients had infectious complications. A review ${ }^{14}$ revealed that the factors responsible could be untreated pre operative urinary tract infection; high perfusion pressure; a longer operative time; toxin absorption and intra-operative collection system perforation; and poor drainage ofthe pelvi-calyceal system after surgery. Delayed haemorrhage is mainly caused by renal arteriovenous fistulae, pseudoaneurysms and infections. One of our patients was monitored carefully for three weeks for delayed haemorrhage and underwent urinary bladder wash and clot evacuation twice. Displacement of a double-J stent is also common after surgery. The incidence reported was as in an average of $2 \% .{ }^{14} \mathrm{~A}$ displaced stent could lead to patient discomfort, infection and haemorrhage.

\section{CONCLUSIONS}

Mini PCNL is as effective as standard PCNL with higher safety margin in low and medium size stone $(10$ to $30 \mathrm{~mm})$. Stone burden is the key denominators for optimal stone free rate. Higher number of tubeless procedures can be performed with lesser duration of hospital stay. Mini PCNL could be a definitive option for a novice urologist to start with percutaneous nephrolithotomy and to gain expertise and excellence with low rate of morbidity. The other independent variables for the safety and efficacy like calyceal puncture technique, types of tract dilators and type of lithotripter needs further scrutiny. A randomisation of the patients for evaluation and comparison of outcome between standard and Mini PCNL among novice surgeon will definitely add on further details on safety and efficacy.

To cite this article: Thapa BB, Basnet B, Rayamajhi BB, Thapa N, Bhandari BB. The safety and efficacy of mini PCNL during Learning Curve. MJSBH. 2019;18(2):42-7.

Conflict of Interest: None declared

\section{REFERENCES}

1. Arslan B, Akbulut MF, Onuk O, Kucuktopcu O, Cilesiz NC, Ozkan A, et al. A comparison of Amplatz dilators and metal dilators for tract dilatation in mini-percutaneous nephrolithotomy. Int Urol Nephrol. 2017;49(4):581-5. DOI: $10.1007 / \mathrm{s} 11255-017-1516-\mathrm{z}$

2. Chand RB, Shah AK, Pant DK, Paudel S. Common site of urinary calculi in kidney, ureter and bladder region. Nepal Med Coll J. 2013;15(1):5-7. PMID:24592784

3. Patel SR, Nakada SY. The modern history and evolution of percutaneous nephrolithotomy. J Endourol. 2015;29(2):153-7. DOI: $10.1089 /$ end.2014.0287

4. Michel MS, Trojan L, Rassweiler JJ. Complications in percutaneous nephrolithotomy. Eur Urol. 2007;51(4):899-906. 
DOI: $10.1016 /$ j.eururo.2006.10.020

5. Wright A, Rukin N, Smith D, De la Rosette J, Somani BK. 'Mini, ultra, micro' - nomenclature and cost of these new minimally invasive percutaneous nephrolithotomy (PCNL) techniques. Ther Adv Urol. 2016;8(2):142-6.

DOI: $10.1177 / 1756287215617674$

6. Jackman SV, Docimo SG, Cadeddu JA, Bishoff JT, Kavoussi LR, Jarrett TW. The "mini-perc" technique: a less invasive alternative to percutaneous nephrolithotomy. World J Urol. 1998;16(6):371-4.

PMID:9870281

7. Bhattu AS, Mishra S, Ganpule A, Jagtap J, Vijaykumar M, Sabnis RB, et al. Outcomes in a large series of minipercs: analysis of consecutive 318 patients. J Endourol. 2015;29(3):283-7.

DOI: 10.1089/end.2014.0290

8. Allen D, O'Brien T, Tiptaft R, Glass J. Defining the learning curve for percutaneous nephrolithotomy. J Endourol. 2005;19(3):279-82.

DOI: $10.1089 /$ end.2005.19.279

9. Tanriverdi O, Boylu U, Kendirci M, Kadihasanoglu M, Horasanli K, Miroglu C. The learning curve in the training of percutaneous nephrolithotomy. Eur Urol. 2007;52(1):206-11.

DOI:10.1016/j.eururo.2007.01.001

10. Lahme S. Miniaturisation of PCNL. Urolithiasis. 2018;46(1):99-106.

DOI: $10.1007 / \mathrm{s} 00240-017-1029-3$

11. Mishra S, Sharma R, Garg C, Kurien A, Sabnis R, Desai M. Prospective comparative study of miniperc and standard PNL for treatment of 1 to $2 \mathrm{~cm}$ size renal stone. BJU Int. 2011;108(6):896-9.

DOI: $10.1111 /$ j.1464-410X.2010.09936.

12. ElSheemy MS, Elmarakbi AA, Hytham M, Ibrahim H, Khadgi S, Al-Kandari AM. Mini vs standard percutaneous nephrolithotomy for renal stones: a comparative study. Urolithiasis. 2018;16(10):207-14. DOI: $10.1007 / \mathrm{s} 00240-018-1055-9$

13. Cheng F, Yu W, Zhang X, Yang S, Xia Y, Ruan Y. Minimally invasive tract in percutaneous nephrolithotomy for renal stones. J Endourol. 2010;24(10):1579-82.

DOI: $10.1089 /$ end.2009.0581

14. Hu G, Guo Z, Liu H, Luo M, Liu M, Lai P, et al. A novel minimally invasive percutaneous nephrolithotomy technique: safety and efficacy report. Scand J Urol. 2015;49(2):174-80. DOI:10.3109/21681805.2014.961545

15. Kukreja RA. Should mini percutaneous nephrolithotomy (MiniPNL/Miniperc) be the ideal tract for medium-sized renal calculi (15-30 mm)? World J Urol. 2018;36(2):285-91.

DOI: $10.1007 / \mathrm{s} 00345-017-2128-\mathrm{z}$.

16. Zeng G, Zhao Z, Wan S, Mai Z, Wu W, Zhong W, et al. Minimally invasive percutaneous nephrolithotomy for simple and complex renal caliceal stones: a comparative analysis of more than 10,000 cases. J Endourol. 2013;27(10):1203-8. DOI: $10.1089 /$ end.2013.0061

17. Sebaey A, Khalil MM, Soliman T, Mohey A, Elshaer W, Kandil W, et al. Standard versus tubeless minipercutaneous nephrolithotomy: A randomised controlled trial. Arab J Urol. 2016;14(1):18-23.

DOI: 10.1016/j.aju.2015.11.005 